\title{
Mechanism and Machine Science Educational Workshop Based on Schröder-Reuleaux Ancient Models of Politecnico di Torino
}

\author{
Walter Franco, Andrea Trivella, Giuseppe Quaglia \\ Department of Mechanical and Aerospace Engineering, Politecnico di Torino, Torino, Italy \\ Email:walter.franco@polito.it, andrea.trivella@polito.it, giuseppe.quaglia@polito.it
}

How to cite this paper: Franco, W., Trivella, A., \& Quaglia, G. (2020). Mechanism and Machine Science Educational Workshop Based on Schröder-Reuleaux Ancient Models of Politecnico di Torino. Advances in Historical Studies, 9, 295-311. https://doi.org/10.4236/ahs.2020.95023

Received: October 30, 2020

Accepted: December 5, 2020

Published: December 8, 2020

Copyright $\odot 2020$ by author(s) and Scientific Research Publishing Inc. This work is licensed under the Creative Commons Attribution International License (CC BY 4.0).

http://creativecommons.org/licenses/by/4.0/

\begin{abstract}
Around the world, there are many collections of models of mechanisms and machine components of historical value. Among these, there is an important collection kept at the Politecnico di Torino, Department of Mechanical and Aerospace Engineering-DIMEAS. It consists of about 85 Reuleaux models manufactured by the Schröder company of Darmstadt in the second half of the $19^{\text {th }}$ century. It includes linkages, gears, cam-follower systems, belt drives, couplings and clutches whose history is reconstructed. Some models are still used effectively today in teaching the science of mechanisms and machine. The paper presents both the important historical collection and the didactic methodology adopted in the course "Mechanics of Automatic Machines" in which students practice the developing of virtual models of some selected mechanisms.
\end{abstract}

\section{Keywords}

History of Mechanisms and Machines, Mechanism Model,

Schröder-Reuleaux Models, Engineering Education, Kinematics Education

\section{Introduction}

Mechanism and Machine Science (MMS) deals with the theory and practice of the geometry, kinematics, dynamics, and control of mechanisms, machine components and machines (Ceccarelli \& Bragastini, 2014). One of the pioneers of MMS, Franz Reuleaux, in the introduction of his famous "The kinematics of machinery" underlines that "Theory and Practice are not antagonistic, as is so often tacitly assumed. (omissis) Theory is not necessarily unpractical, nor Practice unscientific, although both of these things may occur. Indeed in any depart- 
ment thoroughly elucidated by Science the truly practical coincides with the theoretical, if the theory be right." (Reuleaux, 1875).

An effective teaching of the MMS must therefore include both theoretical and practical activities. In order to acquire the skills necessary to carry out an accurate functional study of mechanisms and machine components, it is advisable, for a student, on the one hand to develop rigorous analytical models aimed at calculating the main kinematic quantities, on the other to visualize concretely the movements of the whole mechanism or of some of its parts. The activities are complementary: pure visualization does not allow the student to calculate the main kinematic quantities nor evaluate the effect of the system parameters on the kinematic behavior; the analytical modelling by itself, vice-versa, often provides detailed results that, however, are abstract, not immediately and intuitively associable with the real and that, sometimes, do not make it possible to clarify how the mechanism actually moves.

Today's students have an advantage over their colleagues from previous generations by having easy-to-use calculation and simulation tools available. Once written the kinematic equations of the mechanism under study, it is easy to calculate, by numerical computing software, the trends of the main functional quantities, like positions, speeds, accelerations, centrodes, etc. There are also tools that allow to build models with a graphical interface, and to automatically calculate the kinematic quantities. In addition, 2D and 3D computer graphics and computer-aided design software are also effective, suitable for producing very realistic virtual animations (Arnay et al., 2017; Fu, 2003). All those virtual tools are extremely significant but the physical interaction with a real model provides a deeper understanding and the opportunity to implement the analysis process, which is preliminary to the ability of synthesis and design of mechanisms.

In the past, in the absence of calculation and animation tools, the teachers worked hard in the design and construction of real 2D and 3D models, to be used both to show the trend of mathematical curves (Kempe, 1877; Tedeschini Lalli, 2009; Bartolini Bussi \& Maschietto, 2006), and to allow students to visualize the kinematics of the mechanisms and machine components (Ceccarelli, 2020; Moon, 2007).

Christopher Polhem, Swedish industrialist and inventor of the $17^{\text {th }}$ century, felt that a technical laboratory would be an important part of future engineering education (Tekniska Museet Stockholm). For this reason, he established the Laboratorium Mechanicum in 1697. The collection of wooden models, called mechanical alphabet, was used for educational purposes, to demonstrate simple motion conversion principles and illustrate the machine components that every engineer should know.

As is clear from his publications, Robert Willis (1800-1875) of Cambridge University, one of the founders of MMS, theorist of kinematics, already in 1840 created a collection of mechanical models in wood and brass, both for demonstrations and for educational purposes (Moon, 2003). The models described in 
his text "Principles of mechanism" (Willis, 1870), ten or so, included a four-bar mechanism, a slider-crank mechanism and a universal joint.

During the same period, Ferdinand Redtenbacher (1809-1863), professor at Karlsruhe Polytechnic School, developed, most likely independently, a valuable collection of at least 100 models, documenting their construction in his monograph "Motion Mechanisms" (Redtenbacher, 1857; Wauer et al., 2009).

After his death, his student Franz Reuleaux (1829-1905) at the Technical University of Berlin, Germany, designed and built the largest collection in the world of around 800 models, (Moon 2003; Moon, 2007). After his death, sixty of his models were shipped to the Deutsches Museum of Munich and have thus come to us together with a dozen preserved in Hannover. The other models were entrusted to the care of his student Wilhelm Hartmann (1853-1922), but sadly the most important part of the collection was presumably destroyed during the Second World War.

Fortunately, the designs of Reuleaux's models have been preserved thanks to reproductions of the makers Gustav Voigt ad Jacob Schröder (Bautista Paz et al., 2010).

Gustav Voigt of Berlin built, with the permission and supervision of Reuleaux, about 360 models (Moon, 2004, Voigt, 1907). Some models were to be used for didactic purposes in conjunction with Reuleaux's book "Kinematics of Machinery", as evidenced by the numbers and letters that refer directly to the figures in the text (Moon, 2004).

In 1837 Jacob Peter Schröder (1809-1887) of Polytechnisches Arbeits-Institut of Darmstadt, Germany, teacher of projective geometry, started the production of educational models in cast iron (Moon, 2007). As cited in his catalog (Schröder, 1884), his models are taken from the work of professors Redtenbacher, Reuleaux, Moll, Grove or from practices, based on files from the Darmstadt Polytechnic. For ease of use, the main body is made of good, solid, dry wood. The small parts, such as screws, are made of metal. In some cases, the whole models are made of metal, depending on the need. The models were produced in two different sizes: the larger ones are approximately $400 \mathrm{~mm}$ high, the smaller ones approximately $250 \mathrm{~mm}$. Schröder's models have been awarded in numerous exhibitions: Darmstadt (1837, 1839, 1861, 1876); Berlin (1844); Leipzig (1850); London (1851, 1863); Munich (1854); Paris (1867); Karlsruhe (1869); Wien (1873); Philadelphia (1876); Sidney (1879); Melbourne (1880); Amsterdam (honorary diploma 1889).

In general, in the $19^{\text {th }}$ century, there were different model makers in Germany and France (Moon, 2007), but also in Russia and in Italy.

In the world, several original collections have been preserved in excellent condition up to date, some of which listed by Moon (Moon, 2007). Among the most important constituted by the Voigt-Reuleaux models we want to remember those of the Cornell University of Ithaca (230 pieces) and the University of Porto (130 pieces). As for Schröder's models, we remember the collection of the Fondazione Scienza e Tecnica of Florence (100 pieces) and, not mentioned by Moon, the 
collection of about 85 pieces of the Politecnico di Torino (Marchis, 2009). In Italy, in almost all the historic engineering institutions active before the Second World War one can find collections of educational mechanisms with pieces both built by international and local manufacturers. At the Museum of Engines and Mechanisms of the University of Palermo (museomotori.unipa.it) are preserved more than one hundred didactical models, in metal or wood, which illustrate elementary machines, mechanisms, transmission components, and various steam engine types (Monastero \& Genchi, 2016). The pieces were built by either German or Italian manufacturers e.g., the Schröder Company of Darmstadt, other specialized companies, or even local craftsmen under direct supervision of prof. Elia Ovazza (1852-1928) (Ceccarelli et al., 2016). At the Politecnico di Milano, there is a collection of 40 pieces made by the Società di Incoraggiamento Arti $\mathrm{e}$ Mestieri (SIAM) in the 1920s and 1930s, and widely used by prof Ottorino Sesini and his successors (De Alberti \& Rovida, 1999). These are mostly linkages, joints, and gears. Table 1 integrates the data published in (Moon, 2007) with those relating to the collections of Politecnico di Torino, University of Palermo and Politecnico di Milano. The details of the Bauman Moscow State Technical University collection have been updated in the Table 1, using information deducible from Golovin \& Tarabarin, 2008. The Russian collection consist of original creations of Theory of Mechanism Machines department scientists and postgraduate; original creations of Russian and Soviet engineers and scientists; models reconstructed by foremen of Bauman University according to projects of foreign scientists; copies of interesting models. Some pieces come from collections of Redtenbacher, Reuleaux and Clair.

The educational collections, besides being important from a historical point of view, still today can be valid tools for teaching kinematics. To avoid deterioration due to their use for educational purposes, some suggest making copies by 3D additive manufacturing (Vlasov \& Samoylova, 2016). The original models, however, have a particular charm that encourages their reuse. In these cases, a careful restoration is necessary to preserve its deterioration (Spasskaya \& Terehova, 2016).

The paper deals with the important collection of Schröder-Reuleaux models of the Politecnico di Torino (Italy), and its current use in one of the laboratory activities of the course "Mechanics of Automatic Machines". First a history of the collection is drawn, then a brief description is given. Subsequently the selected mechanisms used in the didactic laboratory are described in detail and finally the didactic methodology adopted for the kinematic study is presented.

\section{The Politecnico di Torino Schröder-Reuleaux Collection}

The history of the collection of didactic models of the Department of Mechanical and Aerospace Engineering-DIMEAS - of the Politecnico di Torino intersects with the history of the Regio Museo Industriale Italiano (Royal Italian Industrial Museum) established in 1862 by Regio Decreto (Royal Decree) of Vittorio 
Table 1. Model collections of kinematic mechanisms in the world (Moon, 2007 integrated with Politecnico di Torino, University of Palermo and Politecnico di Milano collections).

\begin{tabular}{|c|c|c|c|c|}
\hline Location & Institution & \# models & Vintage & Designer \\
\hline Aachen, Germany & RWTH-Technische Hochschule & 300 & modern & \\
\hline Berlin, Germany & Technische Universität & 40 & modern & \\
\hline Boston, MA, USA & Boston Museum of Science & 120 & $1940 \mathrm{~s}$ & Clark/Brown \\
\hline Cambridge, UK & Cambridge University & 40 & $19^{\text {th }}-20^{\text {th }} \mathrm{C}$. & \\
\hline Chemnitz, Germany & Technische Universität & $?$ & modern & \\
\hline Columbia, PA, USA & Nat. Clock and Watch Museum & 80 & $17^{\text {th }}-20^{\text {th }} \mathrm{C}$ & \\
\hline Columbus, $\mathrm{OH}$, USA & Ohio State University & 50 & $1950 \mathrm{~s}$ & Illinois Gear Co. \\
\hline Denmark & Hauck Foundation & $?$ & $18^{\text {th }} \mathrm{C}$ & \\
\hline Dresden, Germany & Technische Universität & 120 & $19^{\text {th }}-20^{\text {th }} \mathrm{C}$. & \\
\hline Florence, Italy & Fondazione Scienza e Tecnica & 100 & $19^{\text {th }} \mathrm{C}$. & Schröder \\
\hline Hannover, Germany & Technische Universität & 20 & 1880 & Reuleaux \\
\hline Hannover, Germany & Technische Universität & 200 & modern & \\
\hline Ithaca, NY, USA & Cornell University & 230 & 1882 & Reuleaux/Voigt \\
\hline Ithaca, NY, USA & Cornell University & 20 & 1869 & Schröder \\
\hline Karlsruhe, Germany & Universität Karlsruhe & 100 & c.1866 & Redtenbacher \\
\hline Kyoto, Japan & Kyoto University Museum & & c. 1890 & Reuleaux/Voigt \\
\hline London, UK & Science Museum & 20 & $19^{\text {th }} \mathrm{C}$. & Schröder \\
\hline London, UK & Victoria and Albert Museum & & & \\
\hline Milan, Italy & Science Museum & & $20^{\text {th }} \mathrm{C}$. & Leonardo copies \\
\hline Milan, Italy & Politecnico di Milano & 40 & $1920-30$ & SIAM \\
\hline Moscow, Russia & Bauman State Tech. Univ. & 600 & $19^{\text {th }}-20^{\text {th }} \mathrm{C}$ & Russian scientists \\
\hline Munich, Germany & Deutsches Museum & 100 & $19^{\text {th }} \mathrm{C}$. & Reuleaux \\
\hline New York, USA & IBM & $?$ & $1950-1970$ & Leonardo copies \\
\hline Newark, NJ, USA & Newark Museum & 160 & $1930 \mathrm{~s}$ & Clark/Brown \\
\hline Paris, France & Musée des Arts et Métiers & $?$ & $19^{\text {th }} \mathrm{C}$. & Schröder \\
\hline Palermo, Italy & University of Palermo & $>100$ & $19^{\text {th }} \mathrm{C}$. & Schröder/Local craftsmen \\
\hline Porto, Portugal & University of Porto & 113 & c. 1890 & Reuleaux/Voigt \\
\hline Prague, Czech Rep. & Technical University & 23 & & Schröder \\
\hline Riga, Latvia & Technical University & $?$ & & Schröder? \\
\hline Rome, Italy & University & 20 & & \\
\hline Stockholm, Sweden & Science Museum & & $18^{\text {th }} \mathrm{C}$. & Polhem \\
\hline Tainan, Taiwan & Nat. Cheng Kung Univ & c. 60 & & Japanese maker \\
\hline Turin, Italy & Politecnico di Torino & 85 & end $19^{\text {th }} \mathrm{C}$. & Schröder \\
\hline Vinci, Italy & Leonardo da Vinci Museum & & $20^{\text {th }} \mathrm{C}$ & Leonardo copies \\
\hline Zurich, Switzerland & ETH & 10 & c. 1880 & Voigt/Reuleaux \\
\hline
\end{tabular}


Emanuele II, king of Italy. Its seat has been fixed in Torino in 1865 (Figure 1). The purpose of the Regio Museo Industriale Italiano was to "promoting industrial education and the progress of industries and commerce", making use, for the first installation, of the objects and devices collected and purchased at the Great London Exposition of 1862 (Bonini, 1902; Marchis, 1986).

According to the organic regulation, in order to promote the progress of industry the Regio Museo Industriale Italiano, among the various activities, had to collect and preserve a permanent historical and progressive exhibition of objects, scientifically ordered and related to industry. The collection was financed with the contribution of 70,000 lire per year from the Municipality and the Province of Turin. In addition, the museum was an industrial higher education institute. The Regio Museo, through teaching accompanied by practical exercises, with the Scuola d'Applicazione per Ingegneri di Torino (established with the Casati Law in 1859), contributed to the training of industrial and civil engineers and provided to specialization on physics, chemistry and mechanics studies applied to industry (Regio Museo Industriale Italiano in Torino, 1891).

Among the compulsory courses for aspiring industrial engineers there were: Kinematics Applied to Machines, Machine Design and Composition, Applied
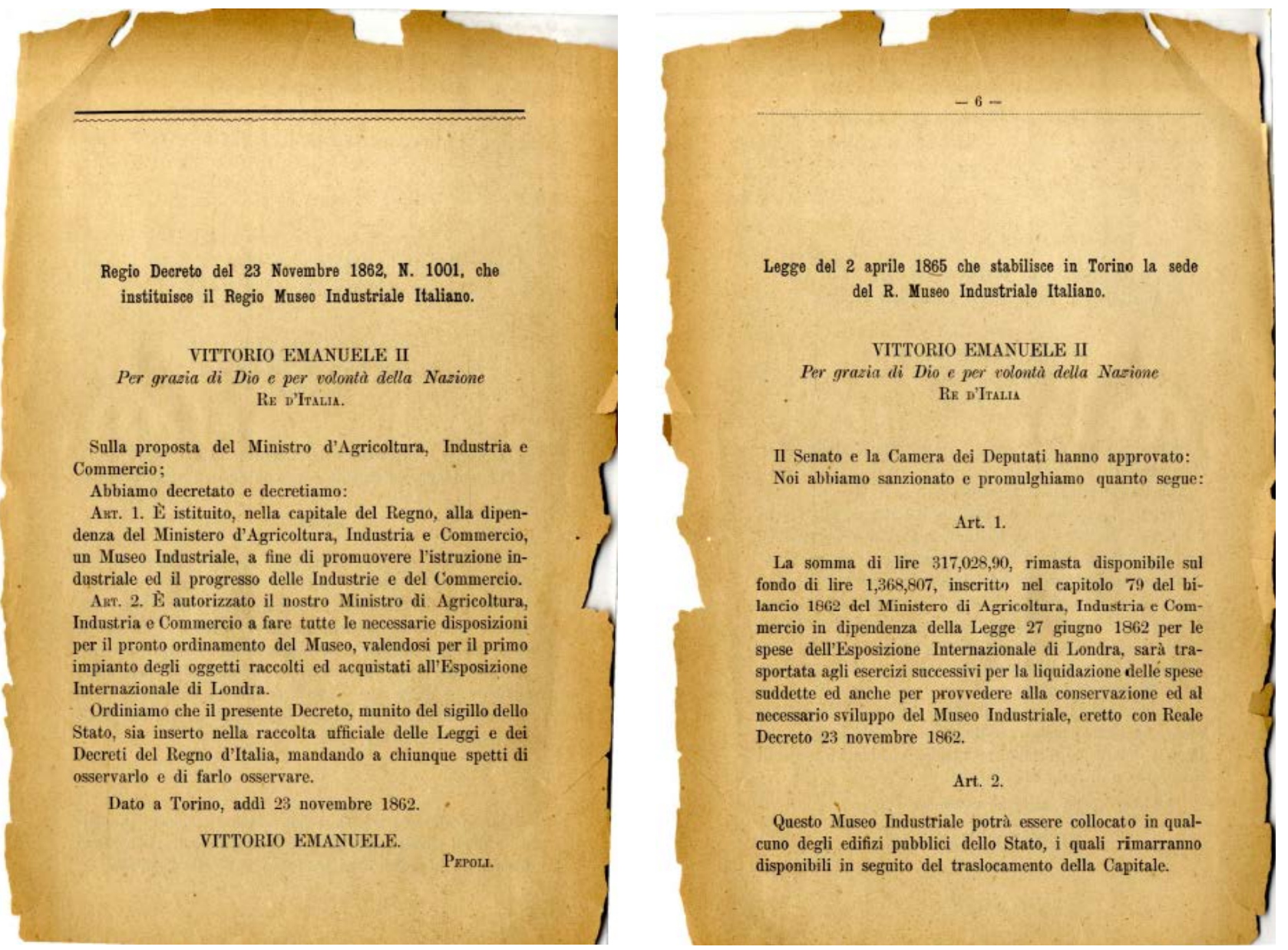

Figure 1. Royal Decree of establishment of Regio Museo Industriale Italiano. 
Mechanics (Cocconcelli, 2021), Practical Hydraulics and Hydraulic Machines. The attention paid to teaching mechanics is evidenced by the presence, in the collections of the Regio Museo, of 89 "educational toys and models of machine elements" (giocattoli istruttivi e modelli di elementi di macchine), as already reported in the publication "Il Regio Museo Industriale Italiano" of 1873 (Figure 2).

At the Institute of Mechanics of the Museum there was a cabinet of Composition of Machines, "intended to make known the shape and proportions of the different parts constituting the machines" with an attached laboratory in which, among others, there were "construction models of all the components and elements of machines [omissis] partly provided by the renowned Company Schröder of Darmstadt and partly made in Italy by mechanical workshops on the basis of drawings supplied by the professor of Composition and Construction of Machines" (Bonini, 1902; Marchis, 1986). In 1906 The Museo Industriale and the Scuola di Applicazione per Ingegneri merged, forming the original nucleus of the Politecnico di Torino (Marchis, 2009).

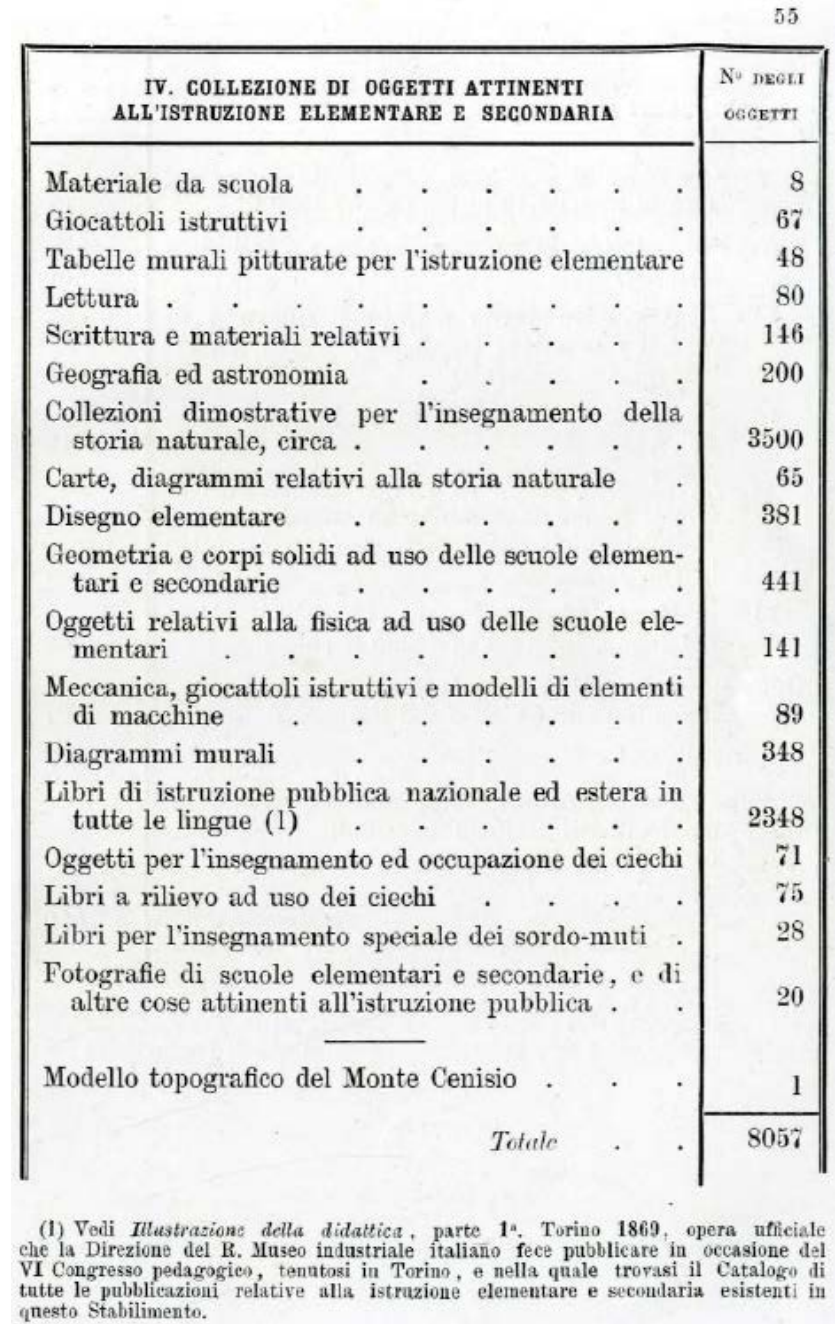

Figure 2. List of objects relating to education of the Regio Museo Industriale Italiano. 
In this way the collection has come almost entirely to us and is currently kept at the Department of Mechanical and Aerospace Engineering-DIMEAS-of the Politecnico di Torino. It consists of about 85 models (Figure 3), for the most part built by the company J. Schröder of Darmstadt, whose catalog is shown in Figure 4.

Each model is marked with the Schröder company logo and the corresponding catalog number (Figure 5). The collection is very varied, and includes, among others, linkages, gears, cam-follower systems, belt drives, couplings and clutches (Figure 6).
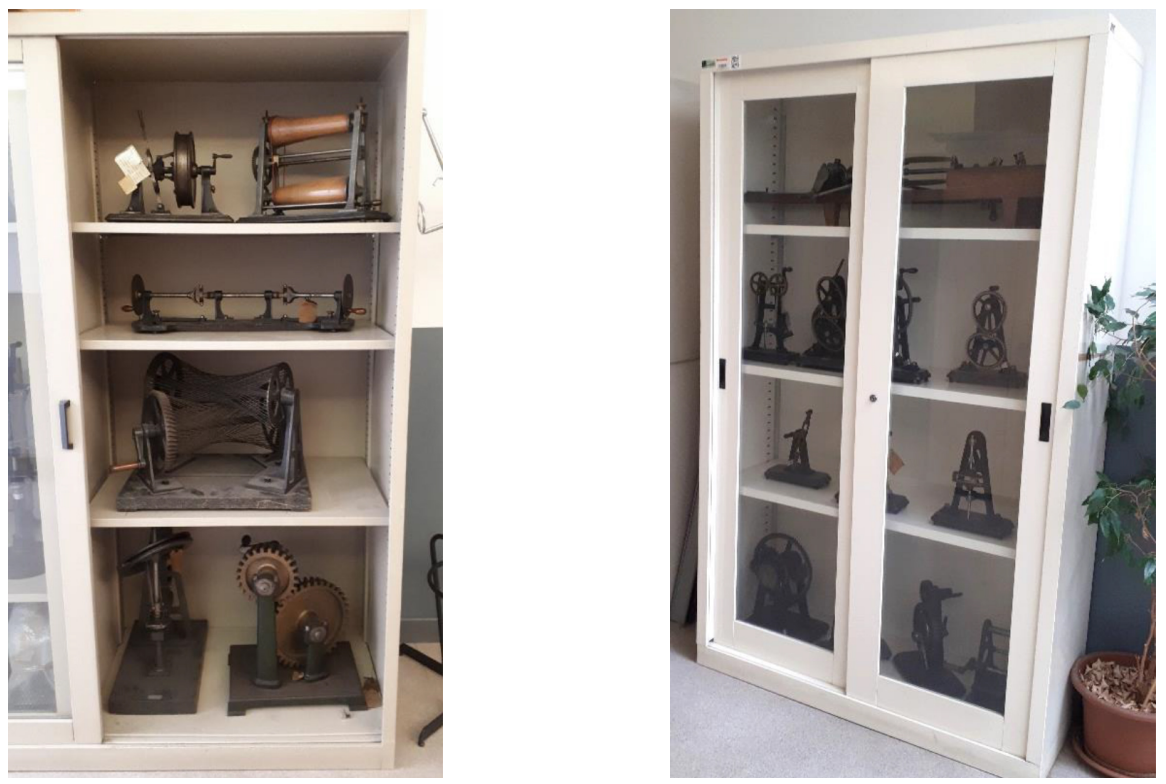

Figure 3. Some cabinets of the Politecnico di Torino collection.
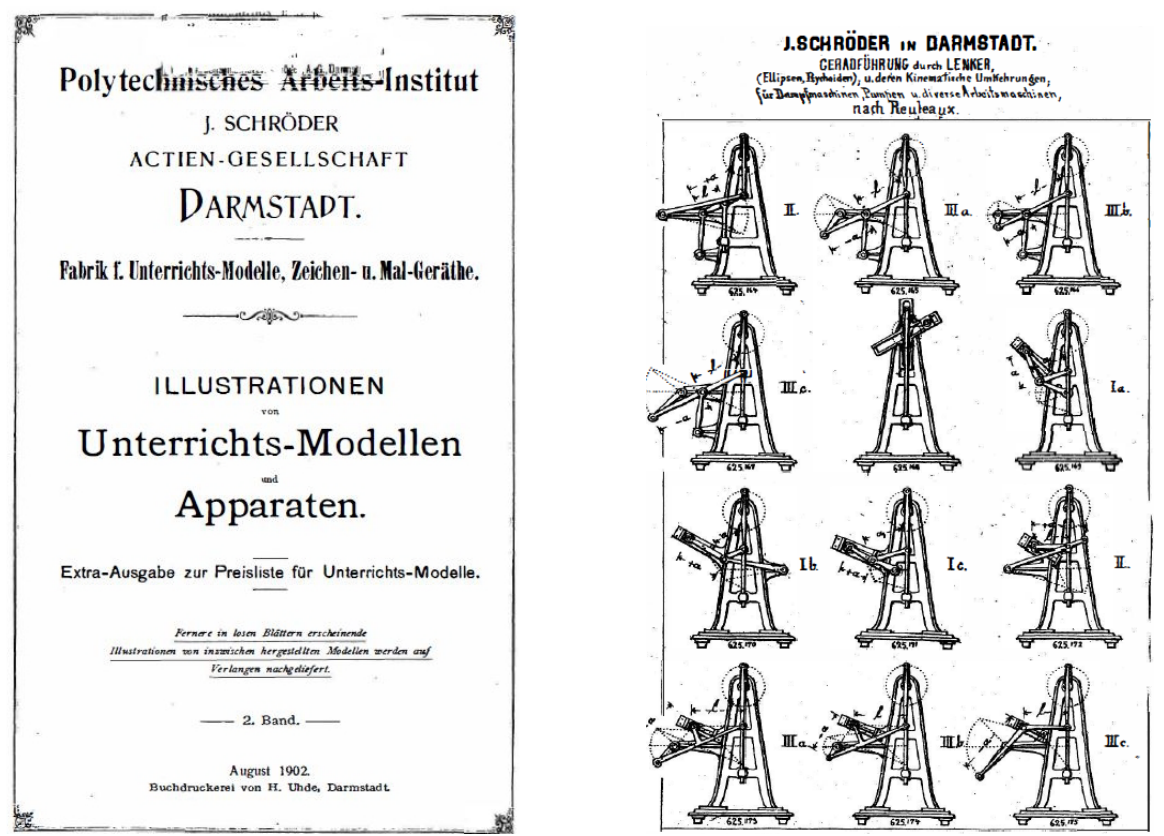

Figure 4. J. Schröder catalog (version 1902). 


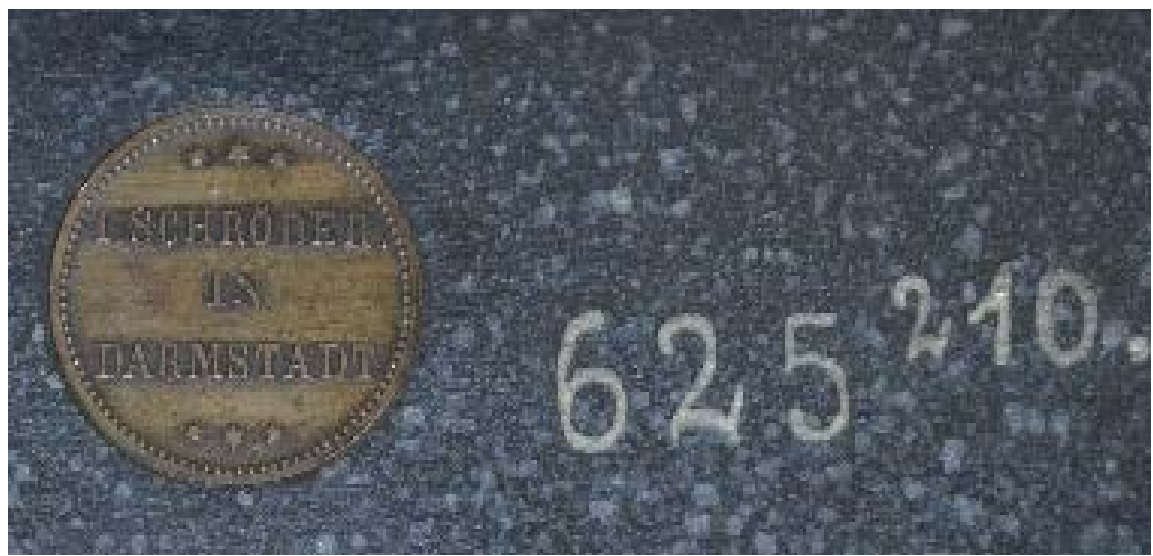

Figure 5. Proprietary brand (trademark) and Schröder catalogue number.
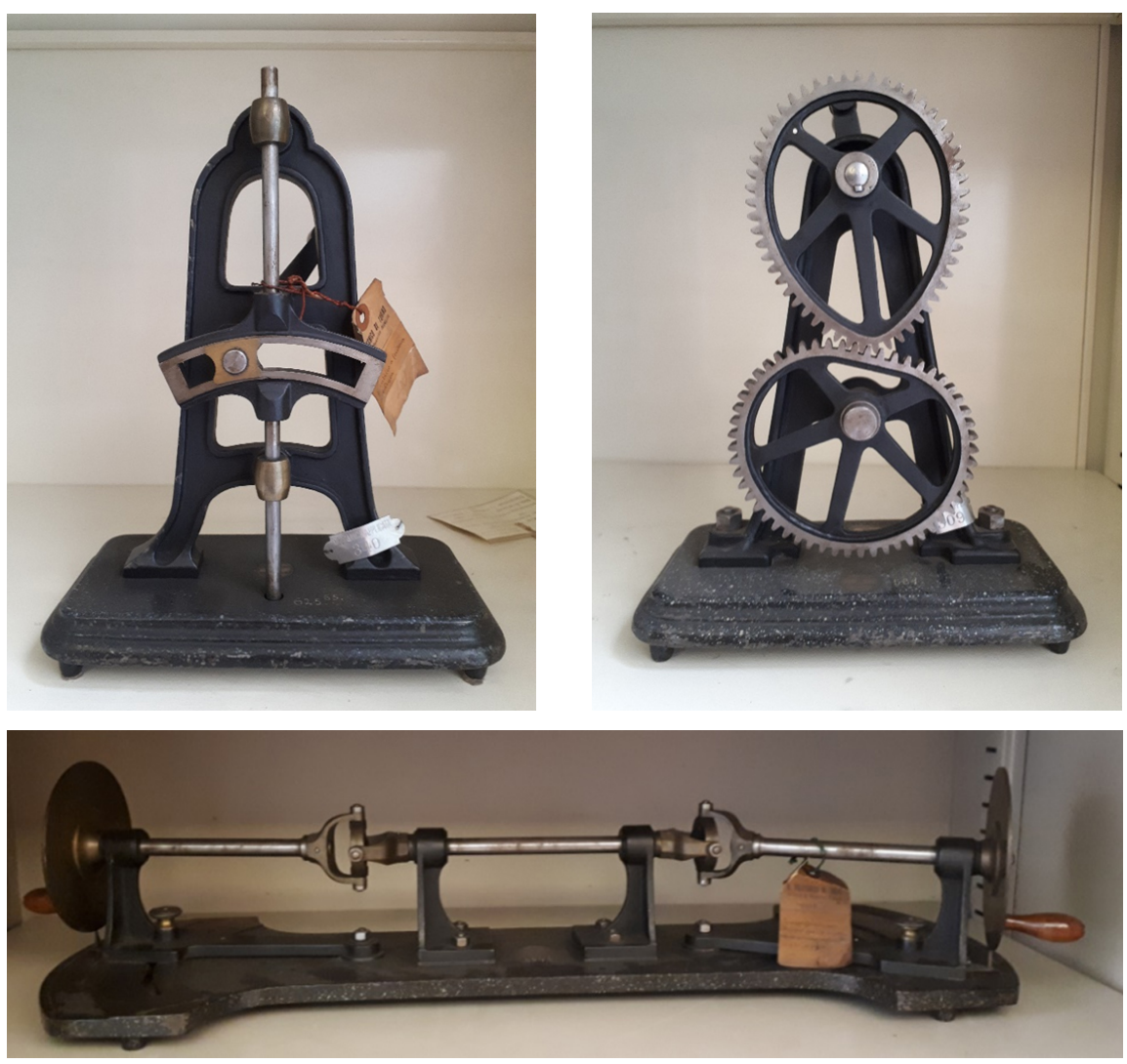

Figure 6. Some models of the collection of Politecnico di Torino-DIMEAS.

\section{The Models Used in the Educational Workshop}

The mechanism models used in the experimental workshop of the course "Mechanics of Automatic Machines" (Figure 7) are approximate or exact straight-line mechanisms and their inversions (Geradführung durch Lenker und deren kinematische Umkehrungen), originally developed for steam engines, pumps and various working machines, as reported in the J. Schröder's catalog:

1) n. $625^{164}$ Evans four-bar approximate straight-line mechanism (EllipsenLenker II Art, angenäherter, normaler mit Scbwingestütze nach Evans); 

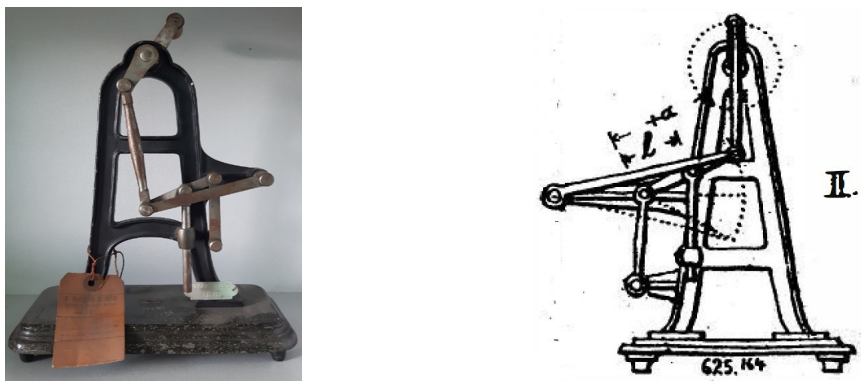

(a)
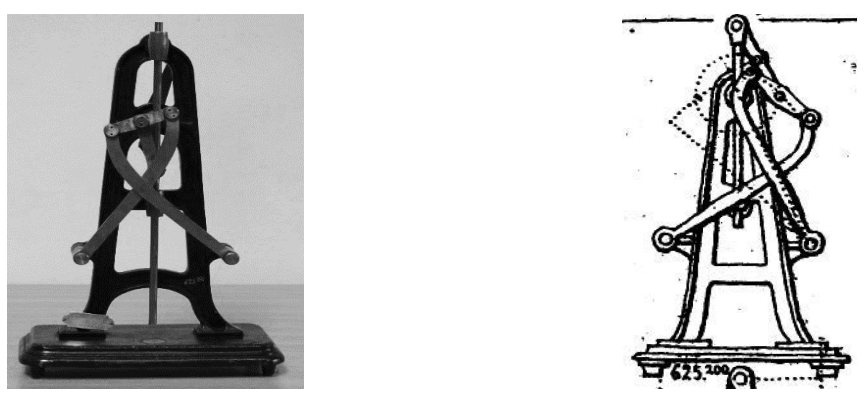

(b)
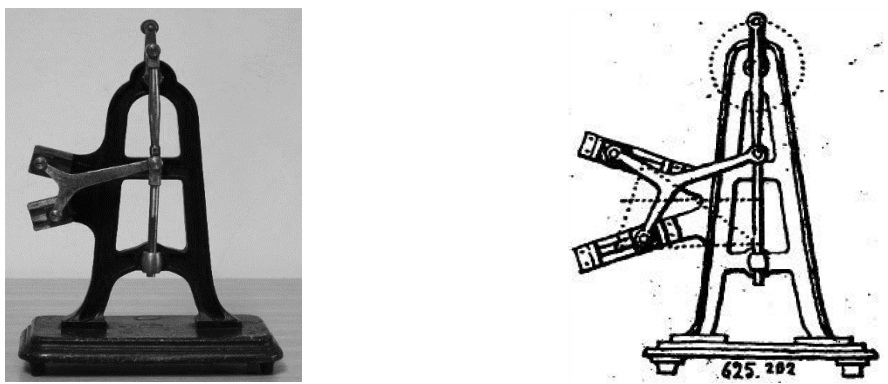

(c)
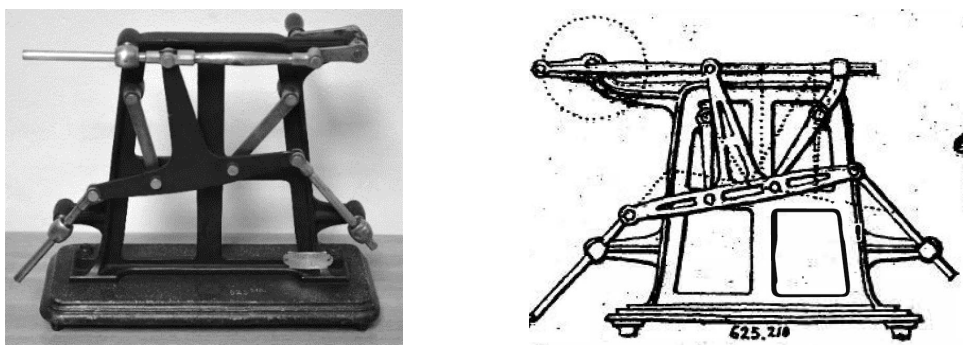

(d)
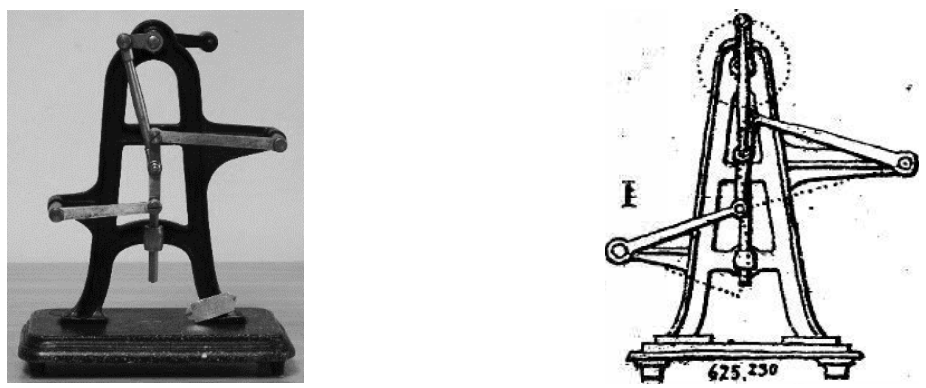

(e)

Figure 7. The mechanisms of the Politecnico di Torino collections used in the educational workshop (left) and the same models in the Schröder's catalog (right). 
2) n. $625^{200}$ Chebyshev four-bar approximate straight-line mechanism (Geschränkter und Ellipsen-Lenker I. Art, a: nach Tenischew);

3) n. $625^{202}$ Reuleaux four-bar slider-crank straight-line mechanism (DreiecksLenker, normaler, gleichschenkliger mit Gleitlagern nach Reuleaux);

4) n. $625^{210}$ Roberts four-bar approximate straight-line mechanism (Desgl. normaler mit Gegenlenkern an inneren Drehpunkten und drei geradgeführten Punkten nach Roberts);

5) n. $625^{230}$ Watt four-bar approximate straight-line mechanism (Lemniscoiden-Lenker-1. Art, die Drehpunkte auf verschiedenen Seiten, ein mittlerer Punkt des Lenkstücks gerade geführt).

\section{The Educational Methodology}

Although today's students have at their disposal very effective calculation and visualization tools, the analytical and virtual models alone do not allow a complete understanding of the general functioning of mechanism or machine components (Franco et al., 2021). In general, a physical didactic model enables an immediate and intuitive experimental visualization of: 1) the type of motion of the single links and of the whole mechanism; 2) the design solutions adopted to avoid geometric interference between links during operation (for example the choice between the cantilever and straddle-mounted revolute joints); 3) the dynamic physical meaning of the toggle positions; 4) the effect of the backlash within kinematic pairs.

In addition, the use of a real model allows students to practice the passage, non-obvious, between the real model and the virtual model: 1) to carry out a mechanical relief; 2) to draw a kinematic scheme starting from the real model by isolating the significant physical phenomena and neglecting the secondary ones; 3) recognizing redundant constraints.

Last but not least it is positive, fascinating and exciting for the student to handle kinematic models conceived and built more than a hundred years ago, testifying that current knowledge is however based on solid roots grown and developed over the centuries. Evidence of this fact is that the same exercise conducted with recent models, or with 3D printed copies of the original models, did not arise the same interest.

Based on these considerations, starting from 2015 we have designed a threehours didactic laboratory which involves the use of historical models. The laboratory is part of the course of "Automatic Machine Mechanics" held at second year of the MSc in Mechanical Engineering. The course is attended by about 140 students, divided in small group of 4 - 5 people.

For each analyzed mechanism, the following activities are proposed:

Experimental functional analysis. It consists in verifying the functioning of the mechanism by observing the types of motion of the links, the role of the joints, including the reasons that determined the choice of the position of the joints and the dimension of the links. The student is asked to divide the mechanism into a 
series of sub-mechanisms, identifying three different functions: the input (or motion generation) mechanism constituted by a crank and connecting rod; the main mechanism aimed at realizing the desired motion (straight-line or approximate straight line coupler curves); the visualization mechanism devoted to show the straight-line coupler curve. By way of example, Figure 8 shows the different parts of the Evans four bar approximate straight-line mechanism. Note that the designer, to show the approximate straight-line motion of the coupler point $E$, used a prismatic joint, whose members are respectively connected to the point $E$ and to the frame.

Geometric relief and schematization. Starting from the given mechanism, students must trace a coherent kinematic model, taking into account the correctness of the symbolism adopted, and taking care to respect the geometric congruence. The main dimensions of the mechanism of Figure 8 are reported in Table 2.

Determination of degrees of freedom. The Grubler's equation allows to calculate the mobility $M$ of a mechanism knowing the number of links $L$, the number of full joints ( 1 degree of freedom joints) $J_{I}$ and the number of half joints ( 2 degree of freedom joints) $J_{2}$ :

$$
M=3(L-1)-2 J_{1}-J_{2}
$$

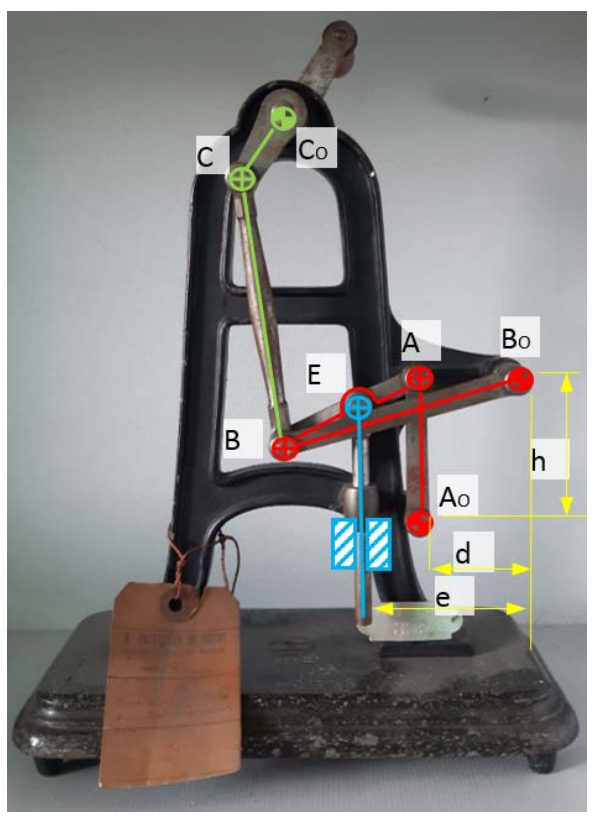

Figure 8. The model of the Evans four bar approximate straight line mechanism: the input mechanism (greeen); the main mechanisms (red); the visualization mechanism (light blue).

Table 2. Main dimensions of the mechanism of Figure 8.

\begin{tabular}{ccccc}
\hline $\mathrm{CoC}=30 \mathrm{~mm}$ & $\mathrm{CB}=105 \mathrm{~mm}$ & $\mathrm{BoB}=95 \mathrm{~mm}$ & $\mathrm{AoA}=60 \mathrm{~mm}$ & $\mathrm{AB}=60 \mathrm{~mm}$ \\
$\mathrm{AE}=25 \mathrm{~mm}$ & $\mathrm{~EB}=35 \mathrm{~mm}$ & $\mathrm{~d}=35 \mathrm{~mm}$ & $\mathrm{~h}=\mathrm{AoA}=60 \mathrm{~mm}$ & $\mathrm{~d}=60 \mathrm{~mm}$ \\
\hline
\end{tabular}


Always considering the example of Figure 8, it is didactically interesting to note that while the number of degrees of freedom of the main mechanism (four-bar linkage) is equal to one, and the same occur for the mechanism consisting of the input mechanism and the main mechanism, the whole mechanism, also including the viewer, has zero degrees of freedom (Table 3). In reality, this does not occur since the point $E$ moves almost rectilinearly and the real prismatic joint of the viewer has a minimum backlash.

Modeling. Using a software for kinematic analysis, like GIM (Petuya et al., 2014), the students must create a model of the given mechanisms. To do this, every student is called to identify and neglect rightly all the constraint redundancies. As an example, (Figure 9) shows the GIM model of the Evans four-bar approximate straight-line mechanism of Figure 8.

Kinematic analysis. After the creation of the GIM model, the simulation software performs the kinematic analysis showing the motion of the whole system or specific points and assessing the effect of the variation of the geometric parameters. The GIM model allows to calculate easily the coupler curves, the fixed and moving centrodes, the position, velocity and acceleration of the points of interest etc. Figure 10 shows, for example, the velocities of the main points of the mechanism under study, and the horizontal displacement of the point $E$.

Table 3. Mobility of the mechanism of Figure 8.

\begin{tabular}{ccccc}
\hline Mechanism & $L$ & $J_{1}$ & $J_{2}$ & $M$ \\
\hline main & 4 & 4 & 0 & 1 \\
input + main & 6 & 7 & 0 & 0 \\
\hline
\end{tabular}

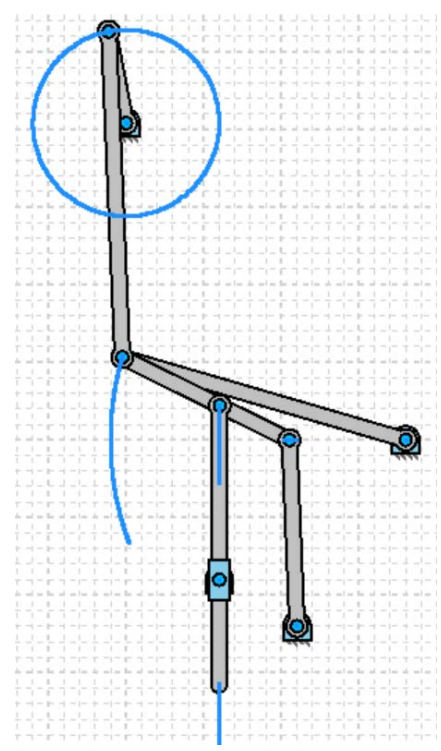

Figure 9. The GIM model of the Evans four bar approximate straight line mechanism. In blue the trajectory of somepoints. 

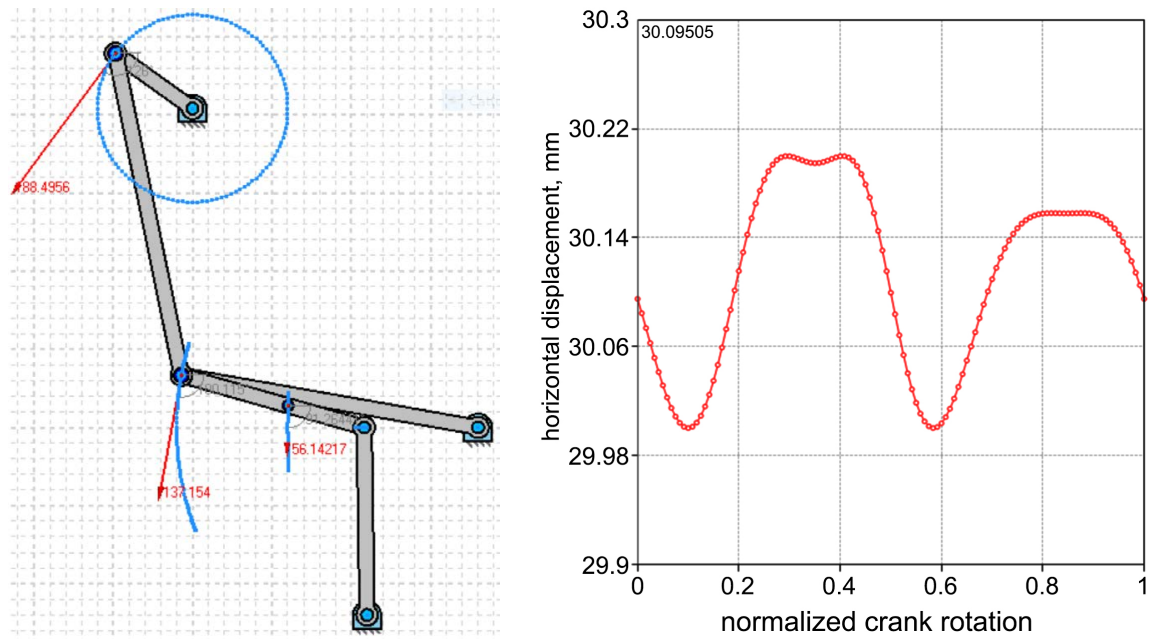

Figure 10. The velocities of the main points of the mechanism under study and the horizontal position of the point $E$ versus the normalized crank rotation.

\section{Conclusion}

The collection of Reuleaux models of Department of mechanical and Aerospace Engineering-DIMEAS-of Politecnico di Torino is one of the most important in the world as regards the models manufactured by company Schröder of Darmstadt. It consists of about 85 models of different types, including linkages, gears, cam-follower systems, belt drives, couplings and clutches. The collection is the legacy of the Regio Museo Industriale Italiano of Turin, established in 1862.

Some models are still used in kinematics practical lectures of a Mechanical Engineering MSc course, "Automatic Machine Mechanics", aimed to develop knowledge of the main types of mechanisms for the transmission and transformation of motion.

The students, during the experimental workshop, are invited to: 1) make an experimental functional analysis of the real historical models; 2) make the relief and sketch a mechanical scheme; 3) calculate the degrees of freedom; 4) study the role of the main parameters on the kinematic behavior using virtual model.

From the beginning of the didactic experimentation, the students have shown interest regarding the activity. In particular, they appreciated the possibility to check their ability to put into practice the knowledge learned during the theoretical lessons. Indeed, the students can exercise and test their skills in carry out an in-depth kinematic performance analysis of a real mechanism and understand the meaning of the synthesis of the same mechanism carried out by its designer.

In addition, the use of the old models for didactic purposes allows students to appreciate their significant technical and historical value, and to comprehend that the current knowledge in the science of mechanisms and machines is the result of a long path that has solid roots in the past.

The historical models conceived at the beginning of the Science of Mechanisms and Machines, despite being over a hundred years old, have maintained 
their effectiveness in reproducing mechanical parts, allowing students of today to play an active role in learning the mechanisms and machine components with a pleasant and interactive methodology.

\section{Acknowledgements}

The authors wish to acknowledge Alfonso Hernández, CompMech, Department of Mechanical Engineering, UPVEHU for the permission to use the $\mathrm{GIM}^{\circledR}$ software. (www.ehu.es/compmech).

The authors wish also to thank the students Daniele Ferraioli, Gabriele Piovano, Alberto Schiavone, Gaetano Mirko Sorrentino and Loris Zilio for providing material developed during the workshop.

\section{Conflicts of Interest}

The authors declare no conflicts of interest regarding the publication of this paper.

\section{References}

Arnay, R., Hernández-Aceituno, J., González, E., \& Acosta, L. (2017). Teaching Kinematics with Interactive Schematics and 3D Models. Computer Applications in Engineering Education, 25, 420-429. https://doi.org/10.1002/cae.21809

Bartolini Bussi, M., \& Maschietto, M. (2006). Macchine matematiche: Dalla storia alla scuola. Milan: Springer Italia.

Bautista Paz, E., Ceccarelli, M., Echávarri Otero, J., \& Muñoz Sanz, J. L. (2010). A Vision on Machines. In A Brief Illustrated History of Machines and Mechanisms (pp. 169205). History of Mechanism and Machine Science Vol. 10, Berlin: Springer. https://doi.org/10.1007/978-90-481-2512-8 8

Bonini, C. F. (1902). Il Regio Museo Industriale in Torino, 1862-1902. Torino.

Ceccarelli, M. (2020). Models of Mechanisms for Teaching and Experimental Activity. Proceedings of the 38th Annual Conference of the "Società Italiana degli Storici della Fisica e dell'Astronomia".

Ceccarelli, M., \& Bragastini, R. (2014). Historical Accounts on the Figure of Engineers and Academic Mission for Their Formation. In New Trends in Educational Activity in the Field of Mechanism and Machine Theory (pp. 3-10). Mechanisms and Machine Science, Vol. 19, Berlin: Springer. https://doi.org/10.1007/978-3-319-01836-2 1

Ceccarelli, M., Sorge, F., \& Genchi, G. (2016). Elia Ovazza, Professor of TMM in Palermo around the End of the 19th Century. In Essays on the History of Mechanical Engineering (pp. 47-63). History of Mechanism and Machine Science, Vol. 31, Berlin: Springer. https://doi.org/10.1007/978-3-319-22680-4 4

Cocconcelli, M. (2021). The Italian Textbooks of Mechanics Applied to Machines in the Modern Age. In V. Niola, \& A. Gasparetto (Eds.), Advances in Italian Mechanism Science (pp. 46-54). Mechanisms and Machine Science, Vol. 91, Cham: Springer.

De Alberti, L., \& Rovida, E. (1999). Historical Heritage of Mechanics Department. Politecnico di Milano. https://doi.org/10.1007/978-3-030-55807-9 6

Franco, W., Quaglia, G., \& Trivella, A. (2021). Using Old Schröder-Reuleaux Models in Modern Kinematics Lectures. Mechanisms and Machine Science, 91, 55-65.

https://doi.org/10.1007/978-3-030-55807-9 7 
Fu, T. (2003). Applications of Computer Simulation in Mechanism Teaching. Computer Applications in Engineering Education, 11, 156-165. https://doi.org/10.1002/cae.10043

Golovin, A., \& Tarabarin, V. (2008). Russian Models from the Mechanisms Collection of Bauman University. History of Mechanism and Machine Science Vol. 5, Berlin: Springer. https://doi.org/10.1007/978-1-4020-8776-9 3

Il Regio Museo Industriale Italiano (1873). Torino, Tipografia C. Favale e comp.

Kempe, A. B. (1877). How to Draw a Straight Line? Mcmillian \& C.

Marchis, V. (1986). Those Strange Mechanisms. Monthly Magazine of the Mechanical, Metallurgical and Allied Manufacturers Associations, Turin, January.

Marchis, V. (2009). Disegnare Progettare Costruire. Centocinquant'anni di arte e scienza nelle collezioni del Politecnico di Torino, Fondazione CRT, Torino.

Monastero, R., \& Genchi, G. (2016). The Museum of Engines and Mechanisms. More than a Century of History of Technology. In Essays on the History of Mechanical Engineering (pp. 201-225). History of Mechanism and Machine Science Vol. 31, Berlin: Springer. https://doi.org/10.1007/978-3-319-22680-4 12

Moon, F. C. (2003). Robert Willis and Franz Reuleaux: Pioneers in the Theory of Machines. Notes and Records of the Royal Society of London, 57, 209-230. https://doi.org/10.1098/rsnr.2003.0207

Moon, F. C. (2004). The Reuleaux Models: Creating an International Digital Library of Kinematics History. International Symposium on History of Machines and Mechanisms: Proceedings HMM 2004, Italy, 12-15 May 2004, 331-344.

Moon, F. C. (2007). The Machines of Leonardo Da Vinci and Franz Reuleaux. Kinematics of Machines from the Renaissance to the 20th Century. History in Mechanism and Machine Science Vol. 2. https://doi.org/10.1007/978-1-4020-5599-7 1

Petuya, V., Macho, E., Altuzarra, O., Pinto, C., \& Hernández, A. (2014). Educational Software Tools for the Kinematic Analysis of Mechanisms. Computer Applications in Engineering Education, 22, 72-86. https://doi.org/10.1002/cae.20532

Redtenbacher, F. (1857). Die Bewegungsmechanismen, Mannheim.

Regio Museo Industriale Italiano in Torino (1891). Annuario per l'Anno scolastico 1890-91. Torino: Tipografia Editrice G. Candeletti.

Reuleaux, F. (1875). Theoretische kinematik: Grundzüge einer theorie des maschinenwesens.

Schröder, J. (1884). Catalog of Reuleaux Models, Darmstadt, Germany.

Spasskaya, D., \& Terehova, N. (2016). Aspects of the Cost-Effectiveness of Restoration Process of the F. Reuleaux Mechanisms. In C. López-Cajún, \& M. Ceccarelli (Eds.), EXplorations in the History of Machines and Mechanisms (pp. 1-7). History of Mechanism and Machine Science Vol. 32, Berlin: Springer.

https://doi.org/10.1007/978-3-319-31184-5 1

Tedeschini Lalli, L. (2009). Mathematical Machines: A Laboratory for Mathematics. Nexus Network Journal, 11, 317-324. https://doi.org/10.1007/s00004-009-0095-4

Tekniska Museet Stockholm. https://www.tekniskamuseet.se

Vlasov, M., \& Samoylova, M. (2016). Application of Rapid Prototyping Technology for Modeling the Mechanisms of F. Reuleaux Collection. In C. López-Cajún, \& M. Ceccarelli (Eds.), Explorations in the History of Machines and Mechanisms (pp. 9-15). History of Mechanism and Machine Science Vol. 32, Berlin: Springer.

https://doi.org/10.1007/978-3-319-31184-5 2

Voigt, G. (1907). Kinematische Modelle nach Professor Reuleaux, Verzeichnis I, II. 
Berlin: G. Voigt.

Wauer, J., Moon, F. C., \& Mauersberger, K. (2009). Ferdinand Redtenbacher (1809-1863): Pioneer in Scientific Machine Engineering. Mechanism and Machine Theory, 44, 16071626. https://doi.org/10.1016/j.mechmachtheory.2009.05.007

Willis, R. (1870). Principles of Mechanism. London: Longmans, Green and Co. 